\title{
Decontamination of the hospital
}

\section{environment: New technologies for}

\section{infection control}

M Maclean*, K. McKenzie, S Moorhead, RM Tomb, JE Coia, SJ MacGregor, JG Anderson

\author{
* Dr Michelle Maclean \\ The Robertson Trust Laboratory for Electronics Sterilisation Technologies \\ University of Strathclyde, 204 George Street, Glasgow, UK, G1 1XW \\ E-mail: michelle.maclean@strath.ac.uk
}

Keywords: environment, decontamination, bacteria, hydrogen peroxide vapor, chlorine dioxide, ozone, steam, ultraviolet light, $405 \mathrm{~nm}$ light, germicidal light, antimicrobial, infection prevention, cross-contamination.

\section{Opinion statement}

Environmental contamination is being increasingly recognized as a significant source of healthcare-associated infection (HAI). Cross-contamination of the patient from the environment can result from the direct transfer of organisms from the air and surfaces, or indirectly from the hospital environment via contact with healthcare workers or equipment. Traditional methods of environmental decontamination, including cleaning with disinfectants, and the standard infection control procedures implemented by modern Health Services, are critical to controlling the spread of potentially pathogenic microbial contaminants from environmental sources to the patient; however there is constant pressure to maintain, and indeed, improve on the standards that are in place to ensure optimal patient care. To address this issue, much research has been directed towards the development and testing of novel 'whole-room' environmental decontamination methods which could be used to enhance hospital hygiene, and consequently reduce the risk of HAI-acquisition from environmental sources. Gaseous methods such as the use of hydrogen peroxide, chlorine dioxide, ozone and steam, as well as ultraviolet and violet-blue visible light methods have all been laboratory tested, and to varying extents, clinically evaluated to assess their efficacy for environmental decontamination. This review article considers these different decontamination technologies, discussing their mechanism of action, antimicrobial efficacy, and advantages and limitations, with a view to providing the reader with a comprehensive overview of the technological advances being developed to reduce the levels of 
environmental contamination around patient areas, thus aiding in the fight against healthcare-associated infection.

\section{The Importance of Environmental Decontamination}

Microbiological contamination of the clinical environment is increasingly being highlighted as a source of infection, with direct contact with contaminated surfaces, indirect contact with contaminated surfaces via the hands of medical staff or equipment, and the air, all being recognised as potential sources of cross-infection [1-3]. High standards of cleaning and disinfection will contribute to minimising the risk of infection, and have been shown to play an important role in controlling outbreaks of infection $[4,5]$.

The hospital environment can quickly become contaminated and act as a reservoir for infection, and evidence shows that significant contamination of nurse's hands can occur from contact with environmental surfaces in the patient's environment [2, 68]. Frequently-touched sites, such as door handles, light switches, bed tables and bed rails, are thought to provide the greatest potential risk for cross-infection [9]. Previous studies have demonstrated that healthcare workers hands can become contaminated through contact with inanimate objects or intact patient skin surfaces, and they can subsequently transfer organisms to other surfaces within the room, and potentially to other patients [7]. Indeed, healthcare workers are almost as likely to contaminate their hands after only touching environmental surfaces in the room as they are when they touch both the patient and environmental surfaces [8].

Environmental cleaning using disinfectants is essential for reducing contamination, however ensuring that the level of cleaning which occurs is adequate can be an issue. Studies have shown that flat surfaces such as bedside tables and locker tops, are cleaned more often than small vertical surfaces such as door handles and light switches [10,11], but also, there are surfaces within the room, such as walls and electronic equipment, which are not routinely cleaned but can still harbour potential pathogens. Another issue is that there can be uncertainty amongst staff about who has responsibility for cleaning patient-related surfaces and medical equipment [9,10]. In addition to these difficulties, organisms such as MRSA, C. difficile, Acinetobacter and vancomycon-resistant enterococci (VRE) can persist on surfaces in the hospital environment - even after discharge cleaning - for significant periods of time, facilitating their transmission between patients, staff and the environment [9,12].

As a consequence of these issues, there has been an upsurge of interest in the development of new 'whole-room' environmental decontamination technologies $[12,13,14]$ which can supplement the standard cleaning and infection control procedures currently in place, with the aim of providing enhanced hygiene and a safer patient environment. This review provides a discussion of a number of the key technologies currently under development for this purpose.

\section{Gaseous Decontamination Methods}

The use of gaseous decontamination, also known as 'chemical-fogging', within clinical settings has emerged as an adjunct measure for inactivation of microorganisms. Gaseous decontamination is a method where either a mist or vapour form of a chemical disinfectant is applied to promote whole room decontamination. Most typically the use of hydrogen peroxide, chlorine dioxide, and ozone have been investigated due to their broad antimicrobial spectra.

Gaseous decontamination presents advantages including the dissipation of gaseous disinfectants allowing decontamination of large, difficult to reach areas, which may be missed or neglected by manual cleaning [12]. However despite this, several limitations are associated with this method of decontamination, particularly the rapid recontamination of rooms within days of re-occupancy, therefore making them more suited to terminal cleaning procedures to provide a deep-clean of the room before the next patient is admitted. A range of gaseous technologies will be discussed in the following sections, and Table 1 provides a summary of the advantages and considerations of the use of gaseous technologies, and the other technologies discussed later in this review.

\subsection{Hydrogen Peroxide}

Hydrogen peroxide $\left(\mathrm{H}_{2} \mathrm{O}_{2}\right)$ is an oxidizing agent used to decontaminate surfaces and objects within hospital rooms and wards. $\mathrm{H}_{2} \mathrm{O}_{2}$ has a broad spectrum of activity against clinically-relevant bacteria, bacterial endospores and viruses [1519], and once decomposed, does not pose any toxic threat to the environment by forming non-toxic by-products of water and oxygen [20]. The mechanism of antimicrobial activity is thought to involve oxidative damage to DNA, proteins and membrane lipids by free hydroxyl and ferryl radicals [15,20]. There are two distinct types of $\mathrm{H}_{2} \mathrm{O}_{2}$ delivery system: aerosolized systems make use of dry mist hydrogen peroxide and are known as aerosolized hydrogen peroxide (aHP) or dry mist hydrogen peroxide (DMHP), and, those which produce $\mathrm{H}_{2} \mathrm{O}_{2}$ vapour are usually referred to as vaporised hydrogen peroxide (VHP) or hydrogen peroxide vapour (HPV) [21]. 
Aerosolized systems include the commercially-available ASP Glosair (formally known as Sterinis) and Oxypharm Nocospray. These systems deliver a pressure-generated fine mist aerosol of $\mathrm{H}_{2} \mathrm{O}_{2}$, and the recommended dose for hospitals is $6 \mathrm{ml} / \mathrm{m}^{3}$ per cycle, during which electrically charged particles circulate in the air, adhere to microbes in the air and on surfaces, inactivating them $[15,16]$. Following the decontamination cycle, no aeration systems are required to remove the $\mathrm{H}_{2} \mathrm{O}_{2}$ as it naturally decomposes (unlike $\mathrm{H}_{2} \mathrm{O}_{2}$ vapour systems) [21].

Clinical testing has proved successful, with a study by Barbut et al. [15] demonstrating the ability of aHP to decontaminate surfaces in hospitals. There was a $91 \%$ decrease in contamination of various surfaces within hospital rooms previously occupied by a $C$. difficile infected patient, compared to a 50\% decrease using conventional cleaning with $0.5 \%$ sodium hypochlorite [15]. More recently the efficacy of an aHP system was tested against clinical isolates from American hospital patients, and $>3-\log _{10}$ reductions of the microorganisms were achieved [22]. The authors concluded that these results indicate that aHP could be beneficial in the clinical setting and, due to its ease of use, its low cost, and the fact that the aerosol decomposes naturally, may make it easier to use than HPV [15,22]

Despite some beneficial features of aHP, HPV has generally been found to have greater efficacy against a range of nosocomial pathogens. Fu et al. [23] demonstrated that HPV had greater efficacy and diffusion than aHP and achieved at least 2- $\log _{10}$ greater inactivation of $C$. difficile, MRSA and A. baumannii over and above the level of inactivation achieved using aHP. The vapour systems generate a 30-35\% w/w vapour of hydrogen peroxide through a high-velocity air stream, with a dose of $10 \mathrm{~g} / \mathrm{m}^{3}$ recommended per cycle [16,23]. Well-documented vapour systems include Steris VHP and Bioquell HPV, with other systems including PEA Hydrogen Peroxide Gas Generator and Hygiene Solutions IC4 system. The Steris VHP system produces non-condensing vaporized hydrogen peroxide, at a constant concentration, which does not condense onto surfaces as the air is continually dried [16,24]. In contrast, the Bioquell system fills the air with hydrogen peroxide vapour, and the vapour subsequently condenses onto surfaces [16]. Both systems are controlled remotely from outside the room and unlike aHP, HPV systems have an aeration unit, as active catalytic conversion is required to aid decomposition of the hydrogen peroxide into non-toxic by-products [18].

Boyce et al. [25] documented the significant reduction in incidence of $C$. difficile associated disease (CDAD) due to HPV terminal cleaning. Comparing the acquisition of CDAD when the epidemic strain NAP1 was present, the study demonstrated a 53\% decrease in cases after implementation of this technology for terminal cleaning [25]. More recently it has been shown that the use of HPV for decontamination of rooms previously occupied by a patient infected with, or carrying, a multidrug-resistant organism (MDRO), reduced the risk of the next occupant acquiring a MDRO by $64 \%$ [26]. Furthermore Chmielarczyk et al. [27] found the use of HPV could control an outbreak of A. baumannii in conjunction with good infection control practice, demonstrating the benefit of hydrogen peroxide vapour used during outbreaks.

Several other considerations should be taken into account before the implementation of $\mathrm{H}_{2} \mathrm{O}_{2}$ technologies for terminal room decontamination. $\mathrm{H}_{2} \mathrm{O}_{2}$ has wide antimicrobial efficacy, however recent data suggests that Geobacillus stearothermophilus spores, which are used as a biological indicator of system efficacy, proved easier to inactivate than MRSA, therefore possibly indicating that the assumed microbial efficacy of $\mathrm{H}_{2} \mathrm{O}_{2}$, due to inactivation of a biological indicator, may not be automatically transferred to other organisms, and further testing may be required to establish the efficacy of $\mathrm{H}_{2} \mathrm{O}_{2}$ against clinical samples [28]. In terms of practical application, $\mathrm{H}_{2} \mathrm{O}_{2}$ is toxic to patients and staff, so rooms need to vacated, which can be impractical when wards have high bed occupancy rates, and treatment takes far longer than standard cleaning [21,29]. $\mathrm{H}_{2} \mathrm{O}_{2}$ toxicity also means that rooms must be sealed during use to prevent leakage of chemicals into the occupied environment [23]. Staff training is important to ensure correct use of the systems, as the equipment has to be carefully placed, especially in the case of aHP to ensure optimal surface contact [12,21], and handheld monitors are also required to ensure no $\mathrm{H}_{2} \mathrm{O}_{2}$ leakage out of the room during decontamination, and that, within rooms, post-treatment levels of $\mathrm{H}_{2} \mathrm{O}_{2}$ are below health and safety limits [12,21]. Alongside this, it is important to note that Hardy et al. [30] found that after $\mathrm{H}_{2} \mathrm{O}_{2}$ vapour decontamination hospital rooms can become quickly re-contaminated with MRSA, therefore although beneficial as a terminal clean, post-use, rooms once again become contaminated and pose a risk to patients.

\subsection{Chlorine Dioxide}

Chlorine dioxide is an Environmental Protection Agency (EPA) registered sterilizer, which is being increasingly investigated as a method of clinical decontamination. Previous research has demonstrated the use of $\mathrm{ClO}_{2}$ for whole facility decontamination, with gaseous $\mathrm{ClO}_{2}$ utilised for decontamination in the wake of a Bacillus anthracis attack on a federal building in 2001 [31]. Much in vitro work has demonstrated extensive antimicrobial properties, with laboratory studies highlighting bactericidal and fungicidal properties [32]. A study by Wilson et al. [33] demonstrated complete inactivation of Stachybotrys chartarum, Penicillium chrysogenum, and Cladosporium cladosporioides fungal spores (6 $\log _{10}$ population) following 24 hours treatment, demonstrating $100 \%$ treatment efficacy at both $500 \mathrm{ppm}$ and $1000 \mathrm{ppm}$. Similarly another study highlighted significant reductions of Bacillus spores, with between 2.7 and $5.9 \log _{10}$ reductions recorded depending on the exposed surface material [34]. 
Currently there are limited studies investigating the use of $\mathrm{ClO}_{2}$ for whole room decontamination. A recent study by Lowe et al [35] investigated decontamination of a hospital room. A selection of common nosocomial bacterial species were transferred onto 10 sites throughout the hospital room and the room was sealed to prevent gas leakage. Following six cycles of $\mathrm{ClO}_{2}$, results demonstrated between 7-10- $\log _{10}$ reductions of all bacteria tested.

Despite extensive antimicrobial properties, a number of significant limitations have been associated with $\mathrm{ClO}_{2}$ gas including explosive properties, thus limiting commercial storage. Furthermore the ability to degrade and discolour certain materials limits whole room applications. Also logistic problems are also a major concern, since rooms need to be vacated and securely sealed to ensure no patient or staff exposure, due to the potential for $\mathrm{ClO}_{2}$ to cause respiratory irritations.

\subsection{Ozone}

Ozone is a strong oxidizing agent used for inactivation of vegetative bacterial cells, however it has shown less efficacy against resilient bacterial spores and fungi [12,36,37]. Despite extensive in vitro research, there are only a limited number of studies investigating ozone within clinical environments.

A study by Doan et al. [38] compared the efficacy of 8 disinfection technologies, including ozone, for decontamination of hospital isolation rooms contaminated with $C$. difficile. Empty isolation rooms were manually cleaned and artificially contaminated with $C$. difficile spores, however results demonstrated only a $1.3-\log _{10}$ reduction following treatment with 25 ppm ozone for 142 minutes.

In order to enhance the antimicrobial efficacy of ozone, increased concentrations are required. However this poses a significant toxicity hazards and potential risk of respiratory irritation. Whilst the use of ozone has been described as a relatively cheap method of decontamination, Doan et al [38] evaluated the cost of multiple decontamination methods, highlighting ozone as the most expensive, at £116 per use, therefore ozone generation would need to be made more costeffective before it can be utilised widely throughout clinical environments.

\subsection{Steam Cleaning}

The use of steam cleaning within hospital settings has generated much interest over recent years, with efficacy demonstrated against a wide spectrum of nosocomial pathogens $[12,39,40]$. Steam can be used as an alternative to chemical disinfection where disadvantages include human hazard, microbial resistance and extensive treatment times.

Steam cleaning, as with most other decontamination technologies presents limitations, such as steam dissipating into water presenting problems with electrical machinery and slip hazards [12,39]. However a recent study by Tanner et al [39] demonstrated the use of saturated steam cleaning. This method provides hotter but drier steam meaning it does not pose issues with decontamination of electronic based equipment. However increased temperature does introduce potential scalding hazards, consequently, increased precaution should be exercised.

Following artificial inoculation onto sample surfaces, results demonstrated complete inactivation of a range of bacteria, fungi and viruses following only 5 seconds treatment [39]. A later study by Sexton et al [40] investigated the reduction of microbial load in 4 separate hospital rooms following treatment with a portable saturated steam vapour system, with results demonstrating up to $2-\log _{10}$ reduction following only 10-20 seconds treatment. Although extensively employed within clinical settings further in situ studies are required to evaluate the efficacy of this system for viral and fungal decontamination.

\section{Light-based Decontamination Methods}

The widespread germicidal properties of light, specifically ultraviolet (UV) light, have long been known, and UV germicidal irradiation (UVGI) has been successfully utilised for various clinical antimicrobial applications. The most germicidal wavelengths of light fall within the UVC region $(240-260 \mathrm{~nm})$, and UVC has traditionally been used for disinfection, particularly for air and medical device decontamination applications [41-42]. UVC light has extremely broad antimicrobial activity, inactivating bacteria, endospores, fungi and viruses, with its action due to the absorption of UV-C photons by DNA and RNA base pairs, which subsequently causes the formation of thymine dimers and other mutations, halting microbial replication [43-45].

More recent advancements in light technologies for infection control have involved the clinical application of continuous and pulsed UV light for 'whole room' decontamination, and also the increasing knowledge and application of the antimicrobial properties of violet-blue visible light. Details of these technologies are provided below.

\subsection{Continuous UV-Light for Whole-Room Decontamination}

Decontamination using continuous UVC-light typically uses systems which employ either a monochromatic lowpressure mercury lamp at $254 \mathrm{~nm}$ or a polychromatic medium-pressure mercury lamp. UVC-light has extensive 
antimicrobial properties, with bacteria, fungi, viruses and protozoan organisms all demonstrating susceptibility, and this broad, efficient action has led to the selection of UV-C for use in many decontamination systems $[41,42,46,47]$. There are currently several commercially available continuous UV-C devices undergoing clinical trials for hospital decontamination, many of which are automatic non-touch disinfection systems, ensuring operator safety.

One such system is the Tru-D SmartUVC Room Decontamination device which utilises continuous-wave UV-light (CWUV) (254nm range) to eradicate pathogens. This device is activated by a wireless remote control with motion sensing technology and delivers a dose between $12,000 \mu \mathrm{Ws} / \mathrm{cm}^{2}$ and $36,000 \mu \mathrm{Ws} / \mathrm{cm}^{2}$ for destruction of vegetative and bacterial spores, respectively [21,46]. The device is placed in the centre of the room and operators control the technology wirelessly from an external location. Several studies have investigated the efficacy of Tru-D UV-C for disinfection of various nosocomial pathogens within the laboratory and clinical environment. Boyce et al. [47] reported a 1.7-2.9 $\log _{10}$ reduction in $C$. difficile spores following inoculation onto stainless steel carrier disks. A further study demonstrated a dose-dependent 2-4 $\log _{10}$ reduction of MRSA, $C$. difficile and VRE using the same system [46]. Towards application for terminal cleaning, it was reported that following traditional terminal cleaning of a room after discharge of MRSA positive patients, $18 \%$ of site tested positive for MRSA; however, following Tru-D disinfection, this was reduced to $0 \%$ [46].

\subsection{Pulsed UV-Light for Whole-Room Decontamination}

Recent work has focused on the use of pulsed, polychromatic xenon flashlamps for microbial inactivation, as this technology enables rapid energy delivery and wide antimicrobial activity, whilst being more environmentally friendly than CW-UV lamps as they do not contain mercury [48-50]. Using this technology, Xenex has developed fullyautomated robotic decontamination systems for clinical room decontamination applications, and have been marketed as 'Germ Zapping Robots'TM. Pulsed xenon UV (PX-UV) emits intense broad spectrum light, rich in UV-C wavelengths in short, high energy pulses, providing rapid decontamination, much faster than that achieved with continuous UV-light. This device has a sporicidal setting of 5 minutes in each position, with a typical patient room taking 3 positions. The PXUV system produces a pulsed flash at a frequency of $1.5 \mathrm{~Hz}$ with an approximate output of $505 \mathrm{~J}$ per pulse and a pulse duration of less than $360 \mu$ s [51]. Clinical testing has demonstrated that, when combined with terminal cleaning, the PXUV disinfection system had the ability to achieve a $100 \%$ reduction in positive cultures of VRE [52]. Furthermore, a recent study by Levin and colleagues reported that three 7-minute exposures of PX-UV following terminal cleaning contributed to a 53\% reduction in the hospital acquired C. difficile infections [51].

Overall, when looking at both pulsed and continuous UVC decontamination technologies, it can be seen that they offer a number of potential advantages, including their reliability and ease of usability, and importantly, the rapid biocidal activity of UVC against a wide range of healthcare-associated pathogens. However, as is the case with the chemicalbased technologies, UVC technologies are also restricted for use for terminal cleaning of vacated rooms due, in this case, to the carcinogenic and mutagenic nature of UVC-light [53]. Additionally, with UV-technologies, there is a limited capacity to decontaminate larger rooms due to light dissipation; similarly as many objects may be out-with the direct line of site, reduced inactivation on indirectly exposed sites may be experienced [54], therefore multiple cycles must be conducted, leaving system operation open to potential human error, as operators must choose appropriate locations thereby requiring more operator time. An issue for future consideration is the degradative effects of long-term UVCexposure on hospital materials and equipment. This is largely unknown and has not yet been evaluated, however the degradative properties of UV-light on plastics and other materials is widely recognised [55].

\subsection{5nm Violet-Blue Light}

More recently, the germicidal properties of violet-blue visible light wavelengths have been demonstrated, and the enhanced safety of these wavelengths compared to UV-light, are paving the way for its exploitation as an alternative light-based environmental decontamination technology.

The high-intensity narrow-spectrum (HINS) light environmental decontamination system (EDS) is a visible light based system which uses low-irradiance violet-blue light, focused on $405 \mathrm{~nm}$, to provide continuous environmental decontamination, a technology that was recently reviewed [56]. Unlike, UVC and chemical-based systems, the EDS is designed for use in occupied environments, providing continuous decontamination of the air and all exposed surfaces in occupied environments. Although not yet commercially available, this user-friendly, ceiling-mounted light source has been evaluated within clinical environments with successful results [57-59].

Studies have investigated use of the system within occupied isolation rooms, and results, generated from the collection of environmental samples before, during and after use of this technology, have provided significant evidence of the efficacy of this system for reducing environmental bioburden around isolation rooms. Studies carried out in an occupied ICU isolation room, demonstrated evidence of the efficacy of the EDS, with a significant 60 to $70 \%$ reductions in both the total viable bacterial counts (TVC) and the staphylococcal bioburden around the environment, over and above the reductions achieved by cleaning alone, with the EDS achieving an almost uniform reduction in bioburden across the 
room surfaces [59]. Studies conducted in Burns Unit isolation rooms also demonstrated the efficacy of the system, with 56-86\% reductions in staphylococcal contamination on surfaces around isolation rooms occupied by MRSA positive patients, and up to $90 \%$ reduction of contamination after $24 \mathrm{~h}$ use in an unoccupied room [57]. Further confirmation of the effectiveness of the system was obtained by switching off the EDS and observing that bacterial contamination levels increased and returned to around pre-treatment levels when operation of the system ceased. In addition to its use for disinfection of occupied isolation rooms, a study by Bache et al [58] demonstrated the efficacy of the system for decontamination of a Burns outpatient clinic, with a $61 \%$ efficacy achieved. Results have also demonstrated its efficacy for significantly reducing the environmental microbial contamination of non-patient environments including a nurses changing area [60].

The antimicrobial action of $405 \mathrm{~nm}$ violet-blue light is caused by oxidative damage resulting from the photo-excitation of porphyrin molecules within exposed microorganisms, and antimicrobial activity is broad, affecting a wide range of clinically-relevant organisms, including MRSA, C. difficile, and A. baumannii [61]. Bacteria, bacterial biofilms, fungi, yeast and bacterial endospores are all susceptible to inactivation, however, as expected, bacterial spores display resilience and require significant doses of light to initiate inactivation [62-64]. The virucidal effects of this technology are also not fully determined, however initial studies using bacteriophage highlight that inactivation is possible, however, as with the spores, higher light doses are required [65].

As mentioned, a major benefit of this technology is that it can be used safely within occupied environments, and this is due to the use of visible light wavelengths, with a lower photon energy than that of UVC-light. However, with this benefit, comes the inherent limitation that inactivation using this low irradiance light is much slower than that of UVClight, requiring exposure times in the order of hours [66] rather than minutes, as is the case with most of the UV and chemical-based systems. This however, means that the system is optimally deployed for continuous decontamination where it can continuously impact on the release of microbial pathogens associated with major bioburden dispersal activities such as bandage changing and bed-making [67], rather than for intense, short-time terminal cleaning. An additional benefit resulting from the use of these longer, lower energy photons, is that there will be significantly less material degradation compared to the UV and chemical-based systems [55].

\section{Conclusions}

HAI resulting from cross-transmission of infectious organisms from the environment is an area gaining increased recognition, and with the appropriate level of patient care, and enhanced environmental cleaning, rates of these infections from environmental sources have the potential to be minimised. For various reasons, ranging from staff time constraints to the fact that not all surfaces around the patient environment are regularly cleaned, a new range of technologies are emerging which focus on providing decontamination of the 'whole-room' environment. This review has described a range of both chemical-based and light-based 'whole-room' decontamination technologies, including hydrogen peroxide, chlorine dioxide, ozone, steam, UV-light and violet-blue light. These technologies each present benefits, ranging from rapid action to the safe decontamination of occupied patient areas, however each technology also has limitations which need to be taken into consideration before implementation.

Although these technologies are being developed for providing enhanced environmental hygiene, they are not a replacement for traditional disinfectant-based cleaning, and it is extremely important that cleaning and infection control procedures are still maintained to the highest standard. For a number of these technologies, efficacy is significantly reduced if there is biological soiling or debris present on surfaces [68,69], therefore reinforcing the strict requirement for traditional cleaning, even when used in combination with new technologies, and these considerations will be very important during the uptake of these technologies.

Overall, there is unlikely to be a single solution to ensuring the cleanest possible patient environment, but the best method is likely to involve complementary use of a number of strategies. For example, the use of routine disinfectant cleaning could be supplemented by use of violet-blue light for continuous room decontamination, and chemical or UV-light based terminal cleans, thus providing effective decontamination before, during and after the patient stay. This type of multi-faceted decontamination strategy, coupled with optimal hand hygiene compliance, is currently likely to be the best way forward for improved environmental decontamination and reducing the risk of patients contracting an HAI from environmental sources.

\section{Disclosure}

No potential conflicts of interest relevant to this article were reported, however, the intellectual property rights of the HINS-light EDS belong to the University of Strathclyde. The University has made all HINS-light EDS for research purposes only and no commercial company currently manufactures or sells this technology. 
Table 1. A summary of the advantage and considerations of a range of environmental decontamination technologies. Manual disinfectant cleaning has been included for comparision.

\section{Disinfection Technology}

Traditional manual cleaning and disinfection

Operational Advantages

Operational Considerations

- Required as integral part of hospital hygiene strategy for the removal of soil and for clean appearance of surfaces.

- Wide antimicrobial efficacy

- Ease of use

- Standard accepted method of cleaning

- Wide antimicrobial efficacy

- Rapid decontamination effect

- The whole room (surfaces and air) is treated

- Good for terminal/deep cleaning

Chlorine dioxide $\left(\mathrm{ClO}_{2}\right)$

Hydrogen peroxide $\left(\mathrm{H}_{2} \mathrm{O}_{2}\right)$

Ozone $\left(\mathrm{O}_{3}\right)$

Steam cleaning

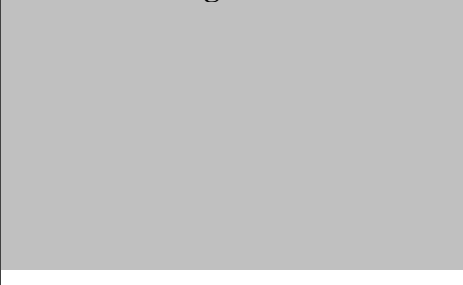

UV-light technology

- Rapid decontamination effect
- The whole room (surfaces and air) can be treated
- Good for terminal/deep cleaning

405nm HINS-light EDS area being cleaned.
- Good for terminal/deep cleaning

- Wide antimicrobial efficacy

- Rapid decontamination effect

- Good for terminal/deep cleaning

- Because the steam cleaning machines incorporate vacuum extraction, dirt, water and contaminants are removed from the

- Safe for use in presence of patients and staff, and non-disruptive - Wide antimicrobial efficacy

- Provides continuous disinfection of the environment (air, exposed surfaces, fabrics, electronic equipment.)

- Continuous use provides decontamination during periods of

heavy microbial dispersal (e.g. bed-making, bandage changing)

- Automated system with no compliance/training problems.

- Environmentally and material friendly / no chemicals involved.

- Uses energy efficient LED technology with low maintenance requirements
- Labour intensive with compliance issues.

- Application is intermittent with variable frequency.

- Only suitable and accessible surfaces are treated.

- Air not treated; Fabrics and electronic equipment often not treated

- Detergents can have limited antimicrobial effectiveness.

- Disinfectants may be toxic and require special safety precautions.

- Safety considerations require experienced operator supervision and training. - Involves use of toxic chemicals.

- Patients and staff cannot be exposed.

- Rooms require sealing and are out of commission during treatment.

- Short term effect as high contamination levels return after several days.

- Some materials can be damaged

- Safety considerations require experienced operator supervision.

- Not usable in presence of patients.

- Disruptive to normal hospital routine.

- Short term effect as high contamination levels return after several days.

- Only suitable and accessible surfaces are treated.

- Air is not treated and fabrics are not effectively treated.

- Not compatible with sensitive electronic equipment.

- Uses dangerous radiation and patients/staff cannot be exposed.

- Room is out of commission during UV treatment.

- Some materials can be damaged by photosensitive degradation.

- If used intermittently, the decontamination effective is short term.

- Microbial resistance to UV can develop.

- Decontamination effect is slower than with chemical/UV-based systems

- Spores require high doses for inactivations

- Full virucidal efficacy has not yet been established

- Most effectively used for continuous disinfection rather than for rapid terminal/deep cleaning applications 


\section{References and Recommended Reading}

Papers of particular interest, published recently,

have been highlighted as:

- $\quad$ Of importance

•. $\quad$ Of major importance

The references (usually 20 or so) should be numbered consecutively in the order of their appearance in the text. References that are used only on a table or figure should appear at the end of the list. Please do not use EndNote.

.. In the reference list, indicate at least a few "papers of particular interest," as described above (one bullet or two?). Please choose these only from references published in the past 3 years (eg, nothing before 2010 if your article will be published in 2014). For each designated reference, provide a sentence or two telling why it is important. 

hospital buildings: fact or fiction? Indoor Built Environ 2003, 12:9-18.

2. Bhalla A, Pultz NJ, Gries DM, Ray AJ, Eckstein EC, Aron DC, Donskey CJ: Acquisition of nosocomial pathogens on hands after contact with environmental surfaces near hospitalized patients. Infect Control Hosp Epidemiol 2004, 25(2):164-166.

3. Boyce JM: Environmental contamination makes an important contribution to hospital infection. $J$ Hosp Infect 2007, 65(S2):50-54.

4. Denton M, Wilcox MH, Parnell P, Green D, Keer V, Hawkey PM, Evans I, Murphy P: Role of environmental cleaning in controlling an outbreak of Acinetobacter baumannii on a neurosurgical intensive care unit. Int Crit Care Nurs 2005, 21:94-98.

5. Pimentel JD, Low J, Styles K, Harris OC, Hughes A, Athan E: Control of an outbreak of multi-drug resistant Acinetobacter baumannii in an intensive care unit and surgical ward. $J$ Hosp Infect 2005, 59:249-253.

6. Boyce JM, Potter-Bynoe G, Chenevert C, King T: Environmental contamination due to methicillinresistant Staphylococcus aureus: possible infection control implications. Infect Control Hosp Epidemiol 1997, 18(9):622-627.

7. Duckro AN, Blom DW, Lyle EA, Weinstein RA, Hayden MK: Transfer of vancomycin-resistant enterococci via health care worker hands. Arch Intern Med 2005, 165:302-307.

8. Hayden MK, Blom DW, Lyle EA, Moore CG, Weinstein RA: Risk of hand or glove contamination after contact with patients colonized with vancomycin-resistant Enterococcus or the colonized patient's environment. Infect Control Hosp Epidemiol 2008, 29(2):149-154.

9. Dancer SJ: The role of environmental cleaning in the control of hospital-acquired infection. J Hosp Infect 2009, 68:39-44.

10. Goodman ER, Platt R, Bass R, Onderdonk B, Yokoe DS, Huang SS: Impact of an environmental cleaning intervention on the presence of methicillin-resistant Staphylococcus aureus and vancomycin-resistant enterococci on surfaces in intensive care unit rooms. Infect Control Hosp Epidemiol 2008; 29(7):593-599.

11. Carling PC, Von Beheren S, Kim P, Woods C: Intensive care unit environmental cleaning: an evaluation in sixteen hospitals using a novel assessment tool. $J$ Hosp Infect 2008, 68:39-44.

12.๑ Dancer SJ: Controlling hospital-acquired infection: Focus on the role of the environment and new technologies for decontamination. Clin Microbiol Rev 2014, 27(4):665-690.

This paper presents a comprehensive review of the role of the environment in HAI, key organisms involved in HAI, and an overview of the role of cleaning and new technologies in infection control.

13. Rutala WA, Weber DJ: Disinfection and sterilization: An overview. Am J Infect Control 2013, 41: S2-S5.

14. Schneider PM: New technologies and trends in sterilization and disinfection. Am J Infect Control 2013, 41: S81-S86.

15. Barbut F, Menuet D, Verachten M, Girou E: Comparison of the efficacy of a hydrogen peroxide dry-mist disinfection system and sodium hypochlorite solution for eradication of Clostridium difficile spores. Infect Control Hosp Epidemiol 2009, 30(6):507-514.

16. Boyce JM: New approaches to decontamination of rooms after patients are discharged. Infect Control Hosp Epidemiol 2009, 30(6):515-517.
17. Chan HT, White P, Sheorey H, Cocks J, Waters MJ: Evaluation of the biological efficacy of hydrogen peroxide vapour decontamination in wards of an Australian hospital. J Hosp Infect 2011, 79(2):125-128.

18. Otter JA, French GL: Survival of nosocomial bacteria and spores on surfaces and inactivation by hydrogen peroxide vapor. J Clin Microbiol 2009, 47(1):205-207.

19. Goyal SM, Chander Y, Yezli S, Otter JA: Evaluating the virucidal efficacy of hydrogen peroxide vapour. $J$ Hosp Infect 2014, 86(4):255-259.

20. Linley E, Denyer SP, McDonnell G, Simons C, Maillard JY: Use of hydrogen peroxide as a biocide: new consideration of its mechanisms of biocidal action. $J$ Antimicrob Chemother 2012, 67(7):1589-1596.

21. Otter JA, Yezli S, Perl TM, Barbut F, French GL: The role of 'no-touch' automated room disinfection systems in infection prevention and control. J Hosp Infect 2013, 83(1):1-13.

This review provides an informative overview of current decontamination technologies such as vaporized and aerosolized hydrogen peroxide, and UV-light and highlights considerations for implementation of these technologies for terminal decontamination.

22. Herruzo R, Vizcaíno MJ, Herruzo I: Quantifying Glosair ${ }^{\mathrm{TM}} 400$ efficacy for surface disinfection of American Type Culture Collection strains and microorganisms recently isolated from intensive care unit patients. J Hosp Infect 2014, 87(3):175-178.

23. Fu TY, Gent P, Kumar V: Efficacy, efficiency and safety aspects of hydrogen peroxide vapour and aerosolized hydrogen peroxide room disinfection systems. $J$ Hosp Infect 2012, 80(3):199-205.

This paper demonstrates the greater efficacy of HPV compared to aHP, and demonstrates the safety requirements for rooms to be sealed during use of aHP, which was previously not thought necessary.

24. Otter JA, Yezli S: A call for clarity when discussing hydrogen peroxide vapour and aerosol systems. $J$ Hosp Infect 2011, 77(1):83-84.

25. Boyce JM, Havill NL, Otter JA, McDonald LC, Adams NM, Cooper T, Thompson A, Wiggs L, Killgore G, Tauman A, Noble-Wang J: Impact of hydrogen peroxide vapour room decontamination on Clostridium difficile environmental contamination and transmission in a healthcare setting. Infect Cont Hosp Epid 2008, 29(8):723-729.

26. Passaretti CL, Otter JA, Reich NG, Myers J, Shepard J, Ross T, Carroll KC, Lipsett P, Perl TM: An evaluation of environmental decontamination with hydrogen peroxide vapour for reducing the risk of patient acquisition of multidrug-resistant organisms. Clin Infect Dis 2013, 56:27-35.

27. Chmielarczyk A, Higgins PG, Wojkowska-Mach J, Synowiec E, Zander E, Romaniszyn D, Gosiewski T, Seifert H, Heczko P, Bulanda, M: Control of an outbreak of Acinetobacter baumannii infections using vaporized hydrogen peroxide. J Hosp Infect 2012, 81(4):239-245.

28. Pottage T, Macken S, Walker JT, Bennett AM: Meticillinresistant Staphylococcus aureus is more resistant to vaporized hydrogen peroxide than commercial Geobacillus stearothermophilus biological indicators. $J$ Hosp Infect 2012, 80(1):41-45.

The results of this study indicate that biological indicators may be more susceptible to hydrogen peroxide decontamination than other bacteria found in the healthcare environment suggesting that the assumed microbial efficacy of hydrogen peroxide may not be transferred to other organisms.

29. Otter JA, Puchowicz M, Ryan D, Salkeld JA, Cooper TA, Havill NL, Tuzzo K, Boyce JM: Feasibility of routinely using hydrogen peroxide vapor to decontaminate rooms 
in a busy United States hospital. Infect Control Hosp Epidemiol 2009, 30(6):574-577.

30. Hardy KJ, Gossain S, Henderson N, Drugan C, Oppenheim BA, Gao F, Hawkey PM: Rapid recontamination with MRSA of the environment of an intensive care unit after decontamination with hydrogen peroxide vapour. J Hosp Infect 2007, 66(4):360-368.

31. United States Environmental Protection Agency (EPA): Anthrax spore decontamination using chlorine dioxide. http://www.epa.gov/pesticides/factsheets/chemicals/chlorin edioxidefactsheet.htm, accessed 16 Dec 2014.

32. Davies A, Pottage T, Bennett A, et al: Gaseous and air decontamination technologies for Clostridium difficile in the healthcare environment. J Hosp Infect 2011, 77:199203.

33. Wilson SC, Wu C, Andriychuk LA et al: Effect of chlorine dioxide gas on fungi and mycotoxins associated with sick building syndrome. Appl Environ Microbiol 2005, 71:5399-5403.

34. Li Y, Zhu N, Jia H, Wu J, Yi Y, Qi J: Decontamination of Bacillus subtilis var. niger spores on selected surfaces by chlorine dioxide gas. J Zhejiang Univ Sci B 2012; 13(4): 254-260.

35. Lowe JJ, Gibbs SG, Iwen PC et al: Impact of chlorine dioxide gas sterilisation on nosocomial organism viability in a hospital room. Int $J$ Environ. Res Public Health 2013, 10:2596-2605.

36. Moat J, Cargill J, Sone J et al: Application of a novel decontamination process using gaseous ozone. Can $J$ Microbiol 2009, 55: 928-933

37. Sharma M, Hudson JB: Ozone gas is an effective and practical antibacterial agent. Am J Infect Control 2008, 36:559-563.

38. Doan L, Forrest H, Fakis A et al: Clinical and cost effectiveness of eight disinfection methods for terminal disinfection of hospital isolation rooms contaminated with Clostridium difficile 027. J Hosp Infect 2012, 82:114121.

39. Tanner BD: Reduction in infection risk through treatment of microbially contaminated surfaces with a novel, portable, saturated steam vapour disinfection system. Am J Infect Control 2009, 37:20-27.

40. Sexton JD, Tanner BD, Maxwell SL et al: Reduction in the microbial load on high touch surfaces in hospital rooms by treatment with a portable saturated steam vapour disinfection system. Am J Infect Control 2011, 39:655-662.

41. Reed NG: The history of ultraviolet germicidal irradiation for air disinfection. Public Health Rep 2010, 125(1):15-27.

42. Moore G, Ali S, Cloutman-Green EA, Bradley CR, Wilkinson MAC, Hartley JC, Fraise AP, Wilson APR: Use of UV-C radiation to disinfect non-critical patient care items: a laboratory assessment of the Nanoclave Cabinet. BMC Infect Dis 2010, 12:174.

43. Chang JC, Ossoff SF, Lobe DC, Dorfman MH, Dumais CM, Qualls RG, Johnson JD: UV inactivation of pathogenic and indicator microorganisms. Appl Environ Microbiol 1985, 49:1361-1365.

44. Sinah RP, Hader DP: UV-induced DNA damage and repair: a review. Photochem Photobio Sci 2002, 1:225236.

45. Hijnen WAM, Beerendonk EF, Medema GJ: Inactivation credit of UV radiation for viruses, bacteria and protozoan (oo)cysts in water: a review. Water Res 2006, 40:3-22.

46. - Nerandzic MM, Cadnum JL, Pultz MJ, Donskey CJ: Evaluation of an automated ultraviolet radiation device for decontamination of Clostridium difficile and other healthcare-associated pathogens in hospital rooms. $B M C$ Infect Dis 2010, 10:197.

This paper focused on the exposure of pathogens to the Tru-D UVC decontamination system in a variety of settings.

47. Boyce JM, Havill NL, Moore B: Terminal decontamination of patient rooms using an automated mobile UV light unit. Infect Control Hosp Epidemiol 2011, 32(8):737-42.

48. Anderson JG, Rowan NJ, MacGregor SJ, Fouacre RA, Farish O: Inactivation of foodborne enteropathogenic bacteria and spoilage fungi using pulsed light. IEEE Trans Plasma Sci 1999, 28:83-88.

49. Wang T, MacGregor SJ, Anderson JG, Woolsey GA: Pulsed ultra violet inactivation spectrum of Escherichia coli. Water Res 2005, 39:2921-2925.

50. Gomez-Lopex VM, Ragaert P, Debevere J, Devlieghere F: Pulsed light for food decontamination: a review. Trends Food Sci Technol 2007, 18:646-473.

51. Levin J, Riley LS, Parrish C, English D, Ahn S: The effect of portable pulsed xenon ultraviolet light after terminal cleaning on hospital-associated Clostridium difficile infection in a community hospital. Am J Infect Control 2013, 41(8):746-748.

A good paper investigating the use of the PX-UV system in a hospital setting in conjunction with routine discharge cleaning.

52. Stibich M, Stachowiak J, Tanner B, Berkheiser M, Moore L, Raad I, Chemaly RF: Evaluation of a Pulsed-Xenon Ultraviolet Room Disinfection Device for Impact on Hospital Operations and Microbial Reduction. Infect Control Hosp Epidemiol 2011, 32(3):286-288.

This paper demonstrated a $100 \%$ reduction in positive cultures of VRE when PX-UV was used in conjunction with terminal cleaning.

53. Matsumura Y, Ananthaswamy HN: Toxic effects of ultra violet radiation on the skin. Toxicol Appl Pharmacol 2004, 195:298-308.

54. Rutala WA, Gergen MF, Weber DJ: Room decontamination with UV radiation. Infect Control Hosp Epidemiol 2010, 31(10):1025-1029.

55. Andrady AL, Hamid SH, Hu X, Torikai A: Effects of increased solar ultraviolet radiation on materials. $J$ Photochem Photobiol B 1998, 46:96-103.

56. $\bullet$ Maclean M, McKenzie K, Anderson JG, Gettinby G, MacGregor SJ: $405 \mathrm{~nm}$ light technology for the inactivation of pathogens and its potential role for environmental disinfection and infection control. $J$ Hosp Infect 2014, 88(1):1-11.

This paper provides a comprehensive review of the antimicrobial properties of $405 \mathrm{~nm}$ light and its application for environmental disinfection.

57. Maclean M, MacGregor SJ, Anderson JG, Woolsey GA, Coia JE, Hamilton K, Taggart I, Watson SB, Thakker B, Gettinby G: Environmental Decontamination of a Hospital Isolation Room using High-Intensity NarrowSpectrum Light. J Hosp Infect 2010, 76(3):247-251.

58. Bache SE, Maclean M, MacGregor SJ, Anderson JG, Gettinby G, Coia JE, Taggart I: Clinical studies of the High-Intensity Narrow-Spectrum light Environmental Decontamination System (HINS-light EDS), for continuous disinfection in the burn unit inpatient and outpatient settings. Burns 2012, 38:69-76.

59. Maclean M, Booth M, MacGregor SJ, Anderson JG, Woolsey GA, Coia JE, Hamilton K, Gettinby G: Continuous decontamination of an intensive care isolation room during patient occupancy using $405 \mathrm{~nm}$ light technology. J Infect Prevent 2013, 14(5):176-181.

60. Coyle A., M. Maclean, J.G. Anderson, G. Gettinby, S.J. MacGregor \& I Taggart. High-Intensity NarrowSpectrum light decontamination of a staff changing room in a burns ward. Burns 2011, 37(S1):S17. 
61. Maclean M, MacGregor SJ, Anderson JG, Woolsey GA: Inactivation of Bacterial Pathogens Following Exposure to Light from a 405-nm LED Array. Appl Environ Microbiol 2009, 75(7):1932-1937.

62. McKenzie K, Maclean M, Timoshkin IV, Endarko E, MacGregor SJ, Anderson JG: Photoinactivation of bacteria attached to glass and acrylic surfaces by $405 \mathrm{~nm}$ light: potential application for biofilm decontamination. Photochem Photobiol 2013, 89: 927-935.

63. Murdoch LE, McKenzie K, Maclean M, MacGregor SJ, Anderson JG: Lethal effects of high intensity violet 405nm light on Saccharomyces cerevisiae, Candida albicans and on dormant and germinating spores of Aspergillus niger. Fungal Biol 2013, 117:519-527.

64. Maclean M, Murdoch LE, MacGregor SJ, Anderson JG: Sporicidal effects of high-intensity $405 \mathrm{~nm}$ visible light on endospore-forming bacteria. Photochem Photobiol 2013, 89(1):120-126.

65. Tomb RM, Maclean M, Herron PR, Hoskisson PA, MacGregor SJ, Anderson JG: Inactivation of Streptomyces phage $\phi C 31$ by 405 nm light: requirement for exogenous photosensitisers? Bacteriophage 2014, 4: e32129.

66. Bache SE, Maclean M, Anderson JG, Gettinby G, Coia JE, MacGregor SJ, Taggart I: Laboratory inactivation of healthcare-associated isolates by a visible HINS-light source and its clinical application in the burns unit. Burns 2011, 37:S6.

67. Bache SE, Maclean M, Gettinby G, Anderson JG, MacGregor SJ, Taggart I: Airborne bacterial dispersal during and after dressing and bed changes on burns patients. Burns, In Press DOI: 10.1016/j.burns. 2014.05.015

This paper provides quantitative evidence of the significant increase in airborne microbial contamination after bed and bandage change of patients.

68. Piskin N, Celebi G, Kulah C, Mengeloglu Z, Yumusak M: Activity of a dry mist-generated hydrogen peroxide disinfection system against methicillin-resistant Staphylococcus aureus and Acinetobacter baumannii. Am J Infect Control 2011, 39(9):757-762.

69. Haas JP, Menz J, Dusza S, Montecalvo MA: Implementation and impact of ultraviolet environmental disinfection in an acute care setting. $A m$ J Infect Control 2014, 42(6), pp.586-90. 